\title{
Letter to the Editor: About glucose and early embryo development in cows described by Leane et al. (2018)
}

\author{
Vimal Selvaraj* and Yves R. Boisclair \\ Department of Animal Science, College of Agriculture and Life Sciences, Cornell University, Ithaca, NY 14853
}

Early embryonic mortality is a significant contributor to reduced fertility of high-yielding dairy cows (Diskin and Morris, 2008). Glucose scarcity has been suggested as a causal factor (Lucy et al., 2014), based on the positive correlation between plasma glucose and fertility in lactating dairy cows (Garverick et al., 2013). Moreover, dairy heifers have inherently higher plasma glucose than high-yielding dairy cows and lower embryonic mortality (Rizos et al., 2010). In a recent publication, Leane et al. (2018) asked whether increasing plasma glucose by intravenous supplementation could improve fertility in late-lactating dairy cows (Leane et al., 2018). They describe changes in conceptus development following a constant intravenous glucose infusion for 1 wk after embryo transfer. Against expectation, they observed reduced elongation of the developing embryos and concluded an adverse effect of glucose. We think it is premature to attribute a negative role to glucose on preimplantation bovine embryo development based on this result. First, the relationship between plasma glucose and uterine luminal fluid glucose levels is not known; Leane et al. (2018) detected no difference in uterine luminal fluid glucose levels between the glucose infusion and control (saline infusion) groups. Second, the baseline plasma glucose levels of lactating cows in this study were already at the higher level reported for heifers or nonlactating cows in previous studies (Maillo et al., 2012; Garverick et al., 2013; Forde et al., 2016), suggesting that the glucose infusion that increased levels by $\sim 10 \mathrm{mg} / \mathrm{dL}$ in Leane et al. (2018) did not really address an insufficiency. Irrespective, it remains quite surprising that glucose infusion did not affect plasma insulin and nonesterified fatty acids, as could be anticipated in late-lactating dairy cows. Given this context, it is highly unlikely that glucose infusion had a direct effect on embryo elongation as presumptively discussed in Leane et al. (2018). Therefore, the role of glucose in preimplantation bovine embryo development remains unresolved and an important question in need of research.

\section{REFERENCES}

Diskin, M. G., and D. G. Morris. 2008. Embryonic and early foetal losses in cattle and other ruminants. Reprod. Domest. Anim. 43(Suppl. 2):260-267.

Forde, N., A. O'Gorman, H. Whelan, P. Duffy, L. O'Hara, A. K. Kelly, V. Havlicek, U. Besenfelder, L. Brennan, and P. Lonergan. 2016. Lactation-induced changes in metabolic status and follicular-fluid metabolomic profile in postpartum dairy cows. Reprod. Fertil. Dev. 28:1882-1892.

Garverick, H. A., M. N. Harris, R. Vogel-Bluel, J. D. Sampson, J. Bader, W. R. Lamberson, J. N. Spain, M. C. Lucy, and R. S. Youngquist. 2013. Concentrations of nonesterified fatty acids and glucose in blood of periparturient dairy cows are indicative of pregnancy success at first insemination. J. Dairy Sci. 96:181-188.

Leane, S., M. M. Herlihy, F. Curran, J. Kenneally, N. Forde, C. A. Simintiras, R. G. Sturmey, M. C. Lucy, P. Lonergan, and S. T. Butler. 2018. The effect of exogenous glucose infusion on early embryonic development in lactating dairy cows. J. Dairy Sci.101:1128511296. https://doi.org/10.3168/jds.2018-14894.

Lucy, M. C., S. T. Butler, and H. A. Garverick. 2014. Endocrine and metabolic mechanisms linking postpartum glucose with early embryonic and foetal development in dairy cows. Animal 8(Suppl. 1):82-90

Maillo, V., D. Rizos, U. Besenfelder, V. Havlicek, A. K. Kelly, M. Garrett, and P. Lonergan. 2012. Influence of lactation on metabolic characteristics and embryo development in postpartum Holstein dairy cows. J. Dairy Sci. 95:3865-3876.

Rizos, D., F. Carter, U. Besenfelder, V. Havlicek, and P. Lonergan. 2010. Contribution of the female reproductive tract to low fertility in postpartum lactating dairy cows. J. Dairy Sci. 93:1022-1029.

Received November 12, 2018.

Accepted November 21, 2018

*Corresponding author: vs88@cornell.edu 